\title{
Comparison of Useful Activities and Changes in Evaluations by Others in Classes through Creating Storytelling and Product Introduction Slides
}

\author{
Isao Miyaji \\ Okayama University of Science, Japan
}

\begin{abstract}
In order to ensure that university students have a sound base of computer knowledge and operating ability, and in order to improve their consciousness regarding their strengths, two types of classes were offered in which storytelling and product slide presentations were performed by creating slides using PowerPoint. The students entered the degree of consciousness and evaluations by others using Excel, and created and submitted reports using Word. This paper investigates useful activities for improving consciousness of the students with regard to these strengths in classes. Purpose of this paper is to compare useful activities. One more purpose is to compare changes in evaluations of others' works. We explore potential reasons for these differences.
\end{abstract}

\section{Introduction}

The Central Education Council in Japan has pointed out the need for a shift to active learning, in which students take the lead in identifying problems and discovering their solutions. It has presented its findings on the implementation of active learning aimed at providing high quality undergraduate education which promotes student-led learning, providing multiple experiences with active learning, and cultivating lifelong learning skills [1].

Earlier, it has become clear through several class implementations that classes can be carried out in which university students are set with the task of repeatedly performing self-evaluations, evaluating others, and making corrections for a selection of problems, and that this approach improves their problem-solving capabilities and cultivates active thinking skills [2]. It is believed that problem-solving abilities can be developed through the task of creating objects that people desire through the creation of articles that people actually use [3]. Following these, many new class methods have been proposed and many attempts have been made to provide effective classes [4], [5], [6].

During a three hour per week mandatory information course held in the second semester for third year university students, a "storytelling creation" course (herein after referred to as "ST"), students created a work about themselves to reflect on themselves using PowerPoint, with the aim of improving their self-understanding, expressive capabilities, and problem-solving abilities [7]. The process of creating these works included evaluation and correction activities, and it was reported that through this the students developed their problemsolving abilities [8]. It was revealed that the software literacy could be improved in the class. The useful activities for improving consciousness were reported [9].

During a two hour per week mandatory information course held in the second semester for third year university students, a "product and book introduction slide creation" course (hereinafter referred to as "PI"), using PowerPoint students created slides introducing products and books in which they had a personal interest, with the aim of improving their research, planning, publicity, and proposal abilities. It was reported that, through this process, they were able to improve not only their PowerPoint operating skills, but also their expressive abilities, planning abilities, publicity skills, and their proposal skills for improving products developed within their own companies [10], [11]. Classification and characteristics of student groups was shown using change of attitude in class for creating slides to present product [11], [12]. The useful activities for improving consciousness were reported [13].

These consisted of active learning, creating works which could only be produced through active and student-led effort. These classes focused on providing students with practical knowledge and applied knowledge. Both classes shared in common the creation of slides using PowerPoint. The themes of the two classes were improving self-understanding and improving project planning and publicity abilities. There have been no reports comparing the effects of these different themes, so we sought to compare the themes and discover what differences there were in the skill and consciousness improvements between the projects. Required times, consciousness and computer literacy in both classes were compared and already reported [14]. Useful activities for improving consciousness and changes in evaluations by others in both classes are investigated and compared. In this paper it is revealed how learning outcomes deference of theme mediates.

This paper is to explain the contents of the classes, of the works themselves, and of the studies. 
Because useful activities for improving consciousness were explored cross-tabulation is analyzed and useful activities are compared. Changes in evaluations by others in classes are also compared. Finally the results are considered.

\section{Contents of Classes}

\subsection{Class objectives}

The objectives of the two classes were for students to directly use computers to provide them with a firm mastery of what they learned regarding computers and enable them to use that knowledge.

For ST, in order to gain a greater understanding of themselves, the students reflected on their past and thought about their current interests and concerns, deliberated about what they wished to do, and organized the results in the form of six slides. For PI, the students decided on products they were interested in and created six slides introducing the product contents, features, key points of interest, advertising, positions with relation to competitors, and improvement proposals. The students needed to think about the themes provided, carry out investigations, and decide on tasks. During this process, the students had to gather information and organize related information and data.

For ST, in order to promote self-understanding, the students had to provide explanations concerning themselves, structured in a format such as "introduction, preliminaries, hobby, leveraging the hobby, future objectives, and conclusion." In the lead up to their job search activities, this project had them analyze themselves and identify what they wanted to do, where their strengths lied, and what they were interested in.

For PI, the students explained their project in a format such as "product name, product contents, product features, advertising, positions with relation to competitors, and improvement proposals," to provide them with an understanding of corporate activities such as research, planning, development, and publicity. The objective of this project was to develop their ability to identify issues, their publicity skills, used in stimulating purchasing desire for the products they develop, and their proposal skills for improving products developed by their companies.

For both of the projects, students were to add movement to their slides in the form of animation to make the content clearer. Students thought about the contents of their explanations and recorded a slide narration in order to create audiovisual slides.

When creating slides, it was important that the slides were visually easily understandable, and the researched contents were explained in an easy to understand manner. The project also made students think about how to arrange images and photographs related to the content, and how to present them.
Students learned the importance of thinking about how to use explanations, images, animation, narration, and the like, in appropriate places, to communicate their ideas and thoughts to others and have the viewers of the slides understand this content. This process developed the students' abilities to express themselves in writing and to express their explanations using images. Working under a deadline for the slides and report also developed their abilities to work systematically.

In these classes, after creating the slides, they presented them to other students, and students evaluated each other. The reactions of the students, in the form of mutual evaluations, were organized into evaluations of others for each person, and each student was provided with the evaluations by others had made of them. Each student looked at the evaluations by other students had made of their works, and revised their works based on them. This mutual presentation and mutual evaluation activity promoted mutual study and collaborative learning between students. They also developed their listening abilities and their abilities to make revisions and improvements. By introducing evaluation activities into the article creation activity of making slides, the classes improved students' consciousness regarding the skills necessary for problem-solving and cultivated their active thinking abilities.

The two classes were laboratory classes, so students were required to create a report. Students entered the necessary information into a report framework and learned how to write technical documents. Students submitted the report to an instructor who read them and pointed out items requiring revision or correction. Through this, students learned how to create more appropriate reports. Furthermore, through their report writing activities, students also cultivated their written and non-written expressive abilities.

This process has high potential for teaching them how to operate computers by creating slides and writing reports, fostering a greater interest in and understanding of computers, and broadening their usage capabilities.

\subsection{Class contents and plan}

The two classes were information courses with the content shown in Table 1. They were mandatory lab classes taught in the second semester for third year students in Information Science Department of A's University. In these classes, each student created two works. Viewing and evaluation were performed two times each, and revisions were performed once each. The class times, number of students, and number of sessions per theme differed, as shown in Table 1. There were two ST themes: self-understanding and the writing of a story for children. There were also 
two PI themes: the introduction of a product and the introduction of a book.

The plan in Table 2 was used to carry out the two classes. During the first class, survey sheets were distributed and a consciousness survey was conducted. Experiment documents were distributed, and, based on them, explanations were provided of the project tasks, class objectives, contents, plans, slide creation methods, experiment methods, and the like. Two sheets of A4 paper were handed out for students to write the content they wished to present. Students were told to think about the contents before the second session, write them on the right side of the paper, and draw a picture in the rectangle at left. Students were then directed to look up information necessary for the creation of their works, and to think about the contents of their projects.

At the second session, narration recording methods and animation insertion methods were explained, and students created slides. An explanation was then provided of how to write up the report. In the following week and thereafter students inserted animations, recorded narration, and completed their slides. At the end, they submitted files containing those slides.

The instructor collected and gathered all the files into a single file, and inserted a slide in between each work requesting that students perform an evaluation. During the last two classes time was allotted for students to view each other's works and evaluation each other. At the start of the class, evaluation forms for evaluating other student's works were handed out, works were shown on the screen, and students watched and evaluated each work. When all works had ended, students entered their evaluations in the evaluation sheets. These evaluation sheet files were then submitted. Evaluation sheets from other students were collected for each work, and students could download all of the evaluations of their works. Students used these evaluations of their works to make revisions. The following week they saw the revised slide presentations, evaluated them again, and then submitted evaluation sheets.

Before each class during which works were evaluated, students submitted $1 / 3$ of their reports. These were returned during class, with areas requiring revision pointed out. The final reports were written before the session following the session in which the works were re-evaluated, and all worksheets of evaluation sheet were entered and submitted.

\subsection{Contents of downloadable files}

E-learning functions were used to make it possible to download slide framework, report framework, and evaluation sheet files. These files were all created and registered by the instructor. A sample slide presentation was registered to make it easy to understand the overall content of the slides to be created.

A report framework was provided to make it easier to understand what content to enter. Six slides were attached, together with a transcript of the narration, so that students could understand the contents of created slides. Evaluation sheet scores were copied and entered into self-evaluation fields, other student presentation evaluation fields, and received evaluation fields, and graphs were attached.

An evaluation form for use in class evaluation activities was attached to the Excel file as an evaluation worksheet. The contents consisted of three self-evaluations, two evaluations of other students' presentations, to received evaluations, an evaluation of consciousness related to improvements before and after the presentation, activities useful for consciousness improvement, and software usage abilities. Students downloaded this file, entered the corresponding contents, and saved the file. The file was then uploaded.

Table 1. Comparison of contents of classes

\begin{tabular}{|c|c|c|}
\hline Subject Conents & Storytelling (ST) & \begin{tabular}{|c|} 
Product \\
Introduction (PI)
\end{tabular} \\
\hline Subject Kinds & $\begin{array}{c}\text { Information } \\
\text { subject }\end{array}$ & $\begin{array}{c}\text { Information } \\
\text { subject }\end{array}$ \\
\hline Class type & Experiment & Experiment \\
\hline Start year & $\begin{array}{l}\text { The latter period } \\
\text { in the third year }\end{array}$ & $\begin{array}{l}\text { The latter period } \\
\text { in the third year }\end{array}$ \\
\hline $\begin{array}{l}\text { Classroom } \\
\text { hours/time }\end{array}$ & $180 \mathrm{~min}$. & $90 \mathrm{~min}$. \\
\hline $\begin{array}{l}\text { No. of classroom } \\
\text { times }\end{array}$ & 10 & 15 \\
\hline $\begin{array}{l}\text { No. of attendance } \\
\text { students }\end{array}$ & 31 & 26 \\
\hline $\begin{array}{l}\text { No. of } \\
\text { times/theme }\end{array}$ & 4 & 6 \\
\hline
\end{tabular}


Table 2. Class plan

\begin{tabular}{|c|c|c|c|c|c|}
\hline \multicolumn{3}{|r|}{ Storytelling (ST) } & \multicolumn{3}{|r|}{ Product introduction (PI) } \\
\hline Time & Works & Plan related to assignment & Time & Works & Plan related to assignment \\
\hline 1 & \multirow{5}{*}{$\begin{array}{l}\text { First } \\
\text { work }\end{array}$} & $\begin{array}{l}\text { Problem description, information retrieval, } \\
\text { considering story about their current interests } \\
\text { and concerns, inputing evaluation sheet } 1\end{array}$ & 1 & & $\begin{array}{l}\text { Problem description, information retrieval, } \\
\text { considering the description to introduce, } \\
\text { inputing evaluation sheet } 1\end{array}$ \\
\hline 2 & & $\begin{array}{l}\text { Explaining how to write a report, submission of } \\
\text { the entry form, creating slide }\end{array}$ & 2 & \multirow{6}{*}{$\begin{array}{l}\text { First } \\
\text { work }\end{array}$} & $\begin{array}{l}\text { Explaining how to write a report, submission of } \\
\text { the entry form, creating slide }\end{array}$ \\
\hline 3 & & $\begin{array}{l}\text { Creating slide, putting the narration, writing } \\
\text { report }\end{array}$ & 3 & & Creating slide, putting the animation \\
\hline 4 & & $\begin{array}{l}\text { Mutual evaluation, inputting evaluation sheet } 2 \text {, } \\
\text { modifying slide, writing report } 2\end{array}$ & 4 & & $\begin{array}{l}\text { Creating slide, recording narration, writing } \\
\text { report } 1\end{array}$ \\
\hline 5 & & $\begin{array}{l}\text { Mutual evaluation, inputting evaluation sheet } 3 \text {, } \\
\text { writing report } 3\end{array}$ & 5 & & $\begin{array}{l}\text { Mutual evaluation, inputting evaluation sheet } 2 \text {, } \\
\text { modifying slide, writing report } 2\end{array}$ \\
\hline 6 & \multirow{5}{*}{$\begin{array}{l}\text { Second } \\
\text { work }\end{array}$} & $\begin{array}{l}\text { Submission of the entry form, information } \\
\text { retrieval, creating slide }\end{array}$ & 6 & & $\begin{array}{l}\text { Mutual evaluation, inputting evaluation sheet } 3 \text {, } \\
\text { writing report } 3\end{array}$ \\
\hline 7 & & Creating slide, adding animation & 7 & & Completing report and evaluation sheet \\
\hline 8 & & $\begin{array}{l}\text { Creating slide, recording narration, writing } \\
\text { report } 1\end{array}$ & 8 & \multirow{6}{*}{$\begin{array}{l}\text { Second } \\
\text { work }\end{array}$} & Submission of the entry form, creating slide \\
\hline 9 & & $\begin{array}{l}\text { Mutual evaluation, inputting evaluation sheet } 2 \text {, } \\
\text { modifying slide, writing report } 2\end{array}$ & 9 & & Creating slide, putting the animation \\
\hline 10 & & $\begin{array}{l}\text { Mutual evaluation, inputting evaluation sheet } 3 \text {, } \\
\text { writing report } 3\end{array}$ & 10 & & $\begin{array}{l}\text { Creating slide, recording narration, writing } \\
\text { report } 1\end{array}$ \\
\hline & & & 11 & & $\begin{array}{l}\text { Mutual evaluation, inputting evaluation sheet } 2 \text {, } \\
\text { modifying slide, writing report } 2\end{array}$ \\
\hline & & & 12 & & $\begin{array}{l}\text { Mutual evaluation, inputting evaluation sheet } 3 \text {, } \\
\text { writing report } 3\end{array}$ \\
\hline & & & 13 & & Completing report and evaluation sheet \\
\hline & & & 14 & & $\begin{array}{l}\text { Revising and submiting report and evaluation } \\
\text { sheet }\end{array}$ \\
\hline & & & 15 & & $\begin{array}{l}\text { Repeating a correction and submission until a } \\
\text { report and an evaluation sheet are completed. }\end{array}$ \\
\hline
\end{tabular}

\section{Study contents}

A questionnaire survey was conducted of activities that contributed to the improvements, their selfevaluations, and their evaluations of other students' presentations. The contents of this study are explained below.

\subsection{Study of activities which contribute to consciousness improvements}

After the slide presentations were completed, for each of the consciousness related to ability items (1 to 30 ), students selected which activities, numbered 1 to 33 , contributed to the consciousness by indicating this in a column at right. Students who selected "Other" entered specific activity contents.

Answers for all students were cross-tabulated, with consciousness listed in rows and activities listed in columns. $\chi^{2}$ test calculation was performed on the cross-tabulation table to determine if there was any significant bias in the frequency distribution. When bias was found, residual analysis was used to determine which items had values which were significantly greater than the expected value. This indicated which activities contributed to which consciousness improvements, and the reasons for these consciousness improvements.

\subsection{Self-evaluation and evaluations of others}

Students entered their self-evaluations, their second self-evaluations, and their third selfevaluations in separate columns. There were a total of 17 evaluation items, concerning explanations (5 items), slides (8 items), and narration (4 items). Selfevaluations were performed after works were completed. Second self-evaluations were performed after seeing other students' presentations and revising their own presentations. Third self-evaluations were performed after seeing other students' presentations again.

Evaluations were performed on the following five point scale. 1. Contents have not been sufficiently entered and the work falls significantly below the required level. 2. Contents do not meet the required level. 3. Contents generally meet the required level. 4. Contents meet the required level. 5. Contents significantly exceed the required level.

When students entered their self-evaluation scores, a graph was drawn at the bottom right of the evaluation worksheet. Students copied this graph and attached it to their reports. The three self-evaluation scores and two evaluations of other students were 
shown on a line graph, making it easy to compare and examine them.

The questions for evaluations of other students' presentations were identical to those for selfevaluations. Students entered evaluation scores after viewing other students' slide presentations. Students entered second evaluation scores after viewing other students' revised slide presentations.

Significant differences for the amount of difference between pre- and post-presentation selfevaluation scores and scores for evaluations of other students' presentations were calculated for each item, and it was determined which evaluation scores increased by a significant degree.

\section{Analysis results}

There were 31 ST respondents and 26 PI respondents. We examined students' consciousness regarding their strengths, both before and after presentations, and used the increase in postpresentation scores vs. pre-presentation scores to determine the degree to which the class achieved its objectives. In the post-presentation consciousness survey, we investigated which activities contributed to improvements in consciousness to identify the reasons for these consciousness improvements. We analyzed the results of evaluations of other students' presentations, after seeing each presentation twice, and used the differences in the scores to determine the degree to which the presentations were revised.

We carried out classes for the two ST themes for 2 themes $\times 4$ weeks $\times 3$ hours $=24$ hours, and for the two PI themes for 2 themes $\times 6$ weeks $\times 1.5$ hours $=$ 18 hours. To compare ST and PI, we used two works of both classes. Below is a comparison of ST and PI works 1 and 2 . In the significant difference test a significance level of 5\% was considered a significant difference. The symbols $\mathrm{m}, \mathrm{SD}$, t, and $\mathrm{p}$ indicate "mean," "standard deviation," "test statistic," and "significance probability." Significance levels of $0.1 \%, 1 \%, 5 \%$, and $10 \%$ are indicated as $* * *, * *, *$, and + , respectively.

\subsection{Results of Clustering of Consciousness through Cluster Analysis Using Number of Activities that Contributed to Consciousness Improvement}

A cross-tabulation table was created for the $31 \mathrm{ST}$ learners and the 26 PI learners, with 30 consciousness related to ability as rows and 33 activities as columns. The 57 ST and PI learners selected a total of 8097 items (4633 for ST and 3464 for PI). This is equivalent to 269.9 items per consciousness and 245.4 items per activity. Tabulation was performed for each cell of the crosstabulation table, creating a 30 row $\mathrm{x} 33$ column cross-tabulation table. The Ward Method was used to perform cluster analysis on the table, using consciousness as cases and activities as variables. The resulting dendrogram showed that consciousness could be clustered into three clusters, as shown in Figure 1. These clusters were named clusters I to III. The horizontal axis in Figure 1 is the degree of dissimilarity and the vertical axis is the consciousness.

Cluster I consisted of 22 consciousness: (24) Sense of satisfaction, (25) Sense of fulfilment, (12) Ability to express one's thoughts in writing, (7) Cultivation of understanding of learned knowledge, (30) Interest in this field, (14) Ability to speak and explain things clearly to others, (15) Ability to make presentations, (13) Ability to express one's thoughts through other media than writing, (28) Ability to think, consider and come up with ideas by oneself, (29) Ability to create and creativity, (27) Ability to create knowledge, (22) Ability to execute, (6) Ability to plan, (8) Ability to study by oneself, (9) Ability to gather information, (10) Ability to organize related information and data, (21) Ability to pursue matters deeply, (11) Ability to analyze information, (20) Ability to correct and improve on one's own thoughts, (26) Ability to solve problems, (5) Ability to set task, and (18) Ability to appropriately selfevaluate one's thoughts. The average number of activities listed as contributing to this 22 consciousness was 264.8, a middling figure roughly the same as the overall average number. Of those, frequencies were relatively high for consciousness such as (30), (5), (7), (22), and (8). Based on this, cluster I can be summarized as "I. Consciousness related to being interested, studying, deepening ones understanding, setting tasks, and carrying out tasks."

Cluster II consisted of four consciousness: (17) Ability to communicate, (23) Ability to collaborate, (16) Ability to listen to what people are saying, and (19) Ability to appropriately evaluate other people's thoughts. The average number of activities listed as contributing to these 4 consciousness was 251.3 , a slightly smaller figure than the average number. This was the group with the lowest number. Of these, frequencies of consciousness such as (19), (23) and (16) were relatively high, so cluster II can be summarized as "II. Consciousness related to communicating, collaborating and evaluating."

Cluster III consisted of four consciousness: (2) Understanding of computers, (4) Expanse of computer usage methods and usage scenes, (1) Interest in and curiosity about computers, and (3) Computer operation skills. The average number of activities listed as contributing to the 4 consciousness was 361.5, the highest average consciousness group. Frequency was relatively high for the 4 consciousness, indicating that there were many activities which contributed to increasing these 


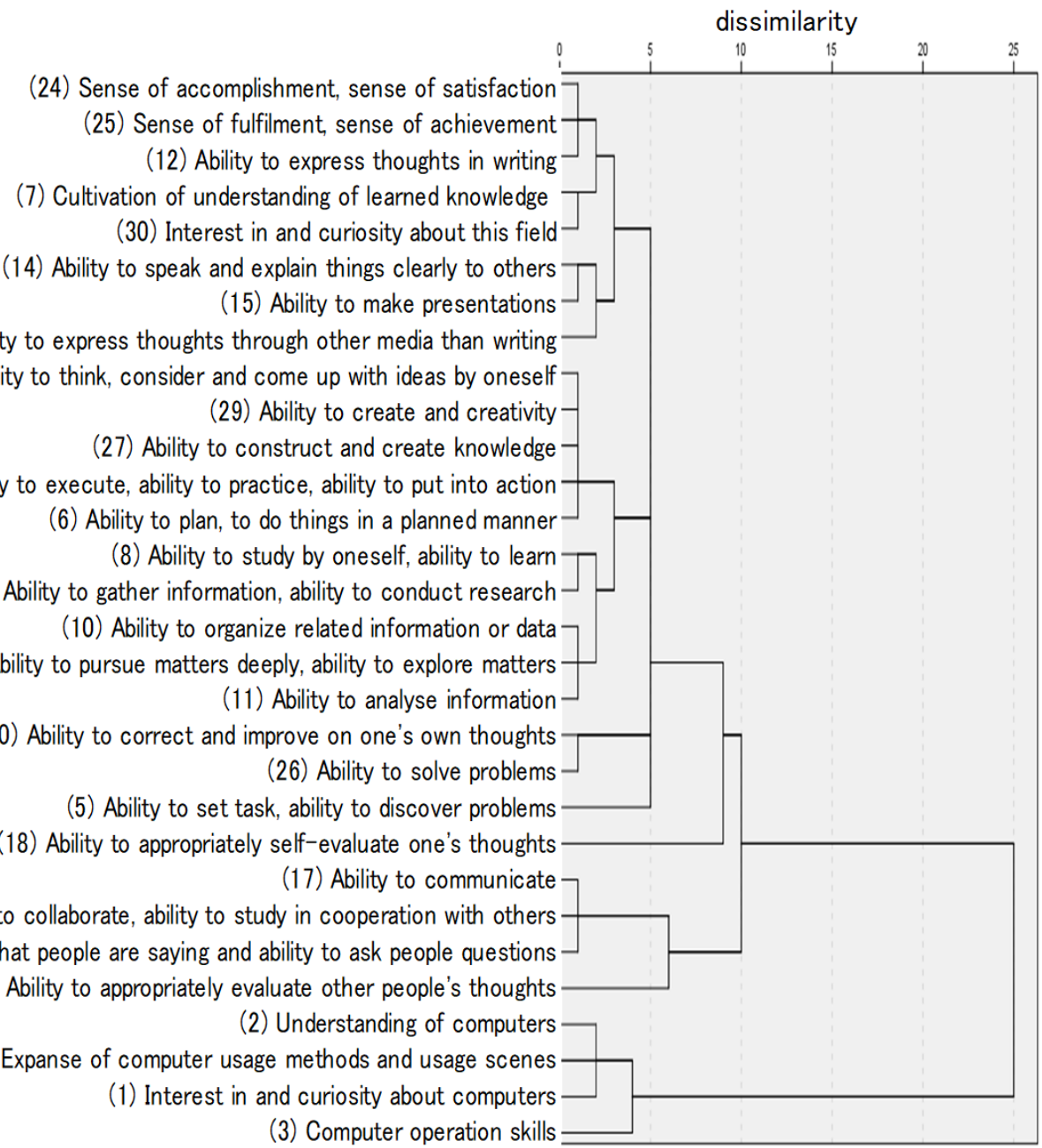

(13) Ability to express thoughts through other media than writing

(28) Ability to think, consider and come up with ideas by oneself

(27) Ability to construct and create knowledge

(22) Ability to execute, ability to practice, ability to put into action

(6) Ability to plan, to do things in a planned manner

(8) Ability to study by oneself, ability to learn

(9) Ability to gather information, ability to conduct research -

(21) Ability to pursue matters deeply, ability to explore matters

(20) Ability to correct and improve on one's own thoughts

(5) Ability to set task, ability to discover problems

(23) Ability to collaborate, ability to study in cooperation with others

(16) Ability to listen to what people are saying and ability to ask people questions

(19) Ability to appropriately evaluate other people's thoughts

(2) Understanding of computers

(4) Expanse of computer usage methods and usage scenes

(3) Computer operation skills

Figure 1. Dendrogram of consciousness clusters determined using cluster analysis

frequencies. Cluster III can be summarized as "III. Consciousness related to computer."

\subsection{Results of clustering of activities through cluster analysis using number of activities that contributed to consciousness improvement}

The Ward Method was used to perform cluster analysis of activities which contribute to consciousness improvements, using the 30 row $x 33$ column cross-tabulation table from Section 4.1, using activities as cases and consciousness as variables. The resulting dendrogram showed that activities could be clustered into three clusters, as shown in Figure 2. These clusters were named clusters 1 to 3 . The horizontal axis in Figure 2 is the degree of dissimilarity and the vertical axis is the activity.

Cluster 1 consisted of 19 activities: 20. to reevaluate own slide presentation, 21 . to reevaluate own slide presentation again, 19. to evaluate own slide presentation, 23. to view others' slide presentation again, 25 . to reevaluate others' slide presentation, 24. to evaluate others' slide presentation, 22. to view others' slide presentation, 31. to rewrite the final report, 32 . to revise the report according to the teacher's feedback, 29. to revise the slide presentation, 3 . to ask to friends about the experiment's content, 4 . to ask to a teacher and TA about the experiment's content, 1 . to listen to an explanation of the experiment's content, 17. to explain the slide presentation to friends, 27. to analyze other students' reevaluations about one's own slide presentation, 28. to compare self-evaluation with other's evaluation, 33. other, 26 . to analyze others' evaluation about the slide presentation, 18. to ask questions about the slide presentation to friends. The average number of activities listed as contributing to these 19 activities was 164.4 , slightly below the overall average number. Of these, activity items such as $1,3,17,18,19$, and 22 had relatively high frequencies, so this cluster was named "1. Activities involving listening to explanations, asking 
questions, viewing created works, evaluating works, and revising works."

Cluster 2 consisted of 9 activities: 15. to add animation in the slide presentation, 16. to record narrations, 13. to create a story, 30. to write a report, 14. to create slide presentation, 2. to understand the overview of the experiment, 10 . to decide the title of a story, 11. to research the content of a story, 12. to organize the findings of this investigation to make them easy to understand. The average frequency of activities listed as contributing to these 9 activities was 315.7 , higher than the overall average frequency.
Of these, activity items such as 14, 12, and 11 had relatively high frequencies, so this cluster was named "2. Activities involving investigating, organizing and creating slide presentations."

Cluster 3 consisted of 5 activities: 8 . to use PowerPoint, 9. to draw figures with Paint, 6. to use Word, 7. to use Excel, and 5. to use a computer. The average number of activities listed as contributing to these 5 activities was 431.8, making it the highestscoring cluster. Frequencies for all activity items were high, so this cluster was named "3. Activities related to computer usage."

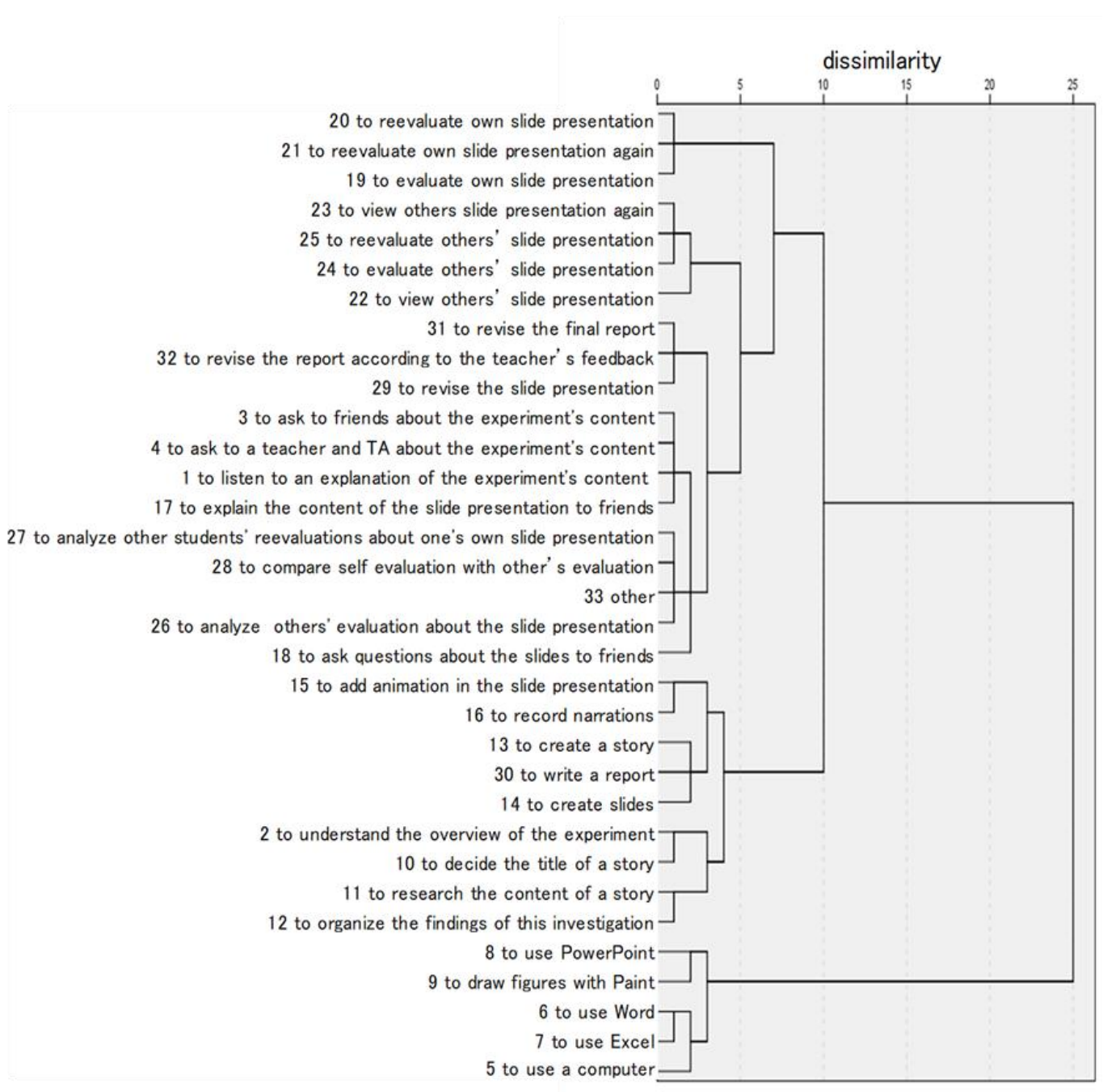

Figure 2. Dendrogram of activity clusters determined using cluster analysis

\subsection{Results of analysis of activities contributing to consciousness improvements based on ST and PI cross-tabulation table}

The cross-tabulation table for consciousness and activities in ST and PI was a 30 row x 33 column table. The dendrogram derived from this table in the previous section was used to rearrange the consciousness and activities in the tabulation table, tabulating frequencies for each cluster, as shown in the upper left of Table 3. This table was used as a $3 \mathrm{x}$ 3 segmented table, and $\chi^{2}$ test calculation was performed on it. This found that frequencies were significantly biased $\left(\chi^{2}(4)=2343.5, \quad \mathrm{p}<.001\right)$. The results of residual analysis are shown in the bottom left of Table 3. In cells recognized as significant, 
cells with positive residual values were marked with a $*$ in the bottom right of Table 3 .

These results were used to identify, from the cells recognized as significant, which activities contributed to improving consciousness with regard to abilities. From these results, we determined that "1. Activities involving listening to explanations, asking questions, viewing created works, evaluating works, and revising works" contributed to the increase of "II. Consciousness related to communicating, collaborating and evaluating."
"2. Activities involving investigating, organizing and creating slide presentations," contributed to the increase of "I. Consciousness related to being interested, studying, deepening ones understanding, setting tasks, and carrying out tasks."

"3. Activities related to computer usage" contributed to the increase of "III. Consciousness related to computer."

Table 3. Results of $\chi^{2}$ test calculation and residual analysis of cross-tabulation based on consciousness and activity clusters

\begin{tabular}{|c|c|c|c|c|c|c|c|}
\hline \multirow[b]{2}{*}{ C } & \multicolumn{4}{|c|}{ Observed frequency } & \multicolumn{3}{|c|}{ Expected frequency } \\
\hline & 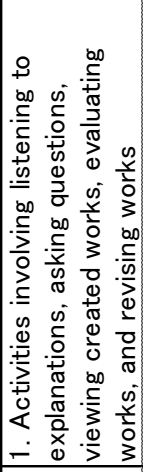 & 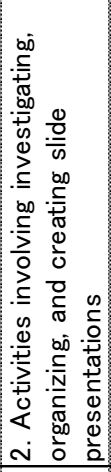 & 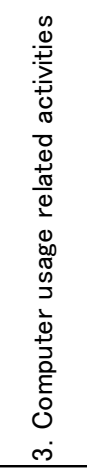 & Total & 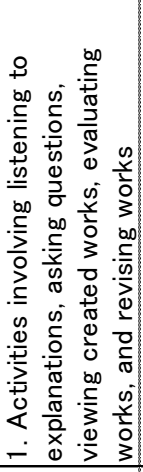 & 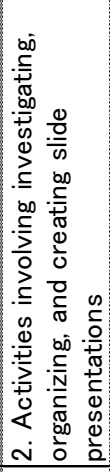 & 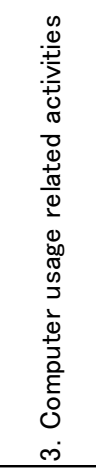 \\
\hline $\begin{array}{l}\text { I. Consciousness related to being interested, } \\
\text { studying, deepening ones understanding, } \\
\text { setting tasks, and carrying out tasks }\end{array}$ & 2167 & 2529 & 1130 & 5826 & 2247.8 & 2024.7 & 1553.5 \\
\hline $\begin{array}{l}\text { II. Consciousness related to communicating, } \\
\text { collaborating and evaluating }\end{array}$ & 785 & 125 & 95 & 1005 & 387.8 & 349.3 & 268.0 \\
\hline III. Consciousness related to computer & 172 & 160 & 934 & 1266 & 488.5 & 440.0 & 337.6 \\
\hline Total & 3124 & 2814 & 2159 & 8097 & 3124 & 2814 & 2159 \\
\hline & \multicolumn{3}{|c|}{ Adjusted residual } & & \multicolumn{3}{|c|}{ Significance probability } \\
\hline $\begin{array}{l}\text { I. Consciousness related to being interested, } \\
\text { studying, deepening ones understanding, } \\
\text { setting tasks, and carrying out tasks }\end{array}$ & -4.1 & 26.2 & -23.7 & & & $* * *$ & \\
\hline $\begin{array}{l}\text { II. Consciousness related to communicating, } \\
\text { collaborating and evaluating }\end{array}$ & 27.5 & -15.9 & -13.2 & & $* * *$ & & \\
\hline III. Consciousness related to computer & -19.9 & -18.0 & 41.3 & & & & $* * *$ \\
\hline
\end{tabular}

\subsection{Comparison of activities contributing to consciousness improvements}

\subsubsection{Activities contributing to $\mathrm{ST}$ consciousness} improvements. As in the previous section, the dendrogram was used to rearrange the consciousness and activities in the ST crosstabulation table, tabulating frequencies for each cluster. The resulting $3 \times 3$ cross-tabulation table was used as a $3 \times 3$ segmented table, and $\chi^{2}$ test calculation was performed on it. This found that frequencies were significantly biased $\left(\chi^{2}(4)=1228.6, p<.001\right)$. The residual analysis was conducted. In cells recognized as significant in the results, cells with positive residual values were the same as the cross-tabulation table in Table 3 for ST and PI combined as shown in the bottom right of Table 4.

4.4.2. Activities contributing to PI consciousness improvements. As in the previous section, the dendrogram was used to rearrange the consciousness and activities in the PI crosstabulation table, tabulating frequencies for each cluster.

The resulting $3 \times 3$ cross-tabulation table was used as a $3 \times 3$ segmented table, and $\chi^{2}$ test calculation was performed on Table 5 . 
Table 4. Results of $\chi^{2}$ test calculation and residual analysis of cross-tabulation based on ST consciousness and activity clusters

\begin{tabular}{|c|c|c|c|c|c|c|c|}
\hline \multirow[b]{2}{*}{ Consc } & \multicolumn{4}{|c|}{ Observed frequency } & \multicolumn{3}{|c|}{ Expected frequency } \\
\hline & 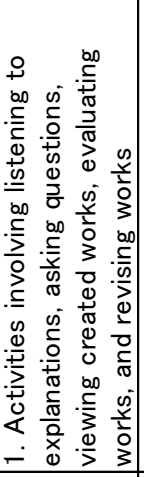 & 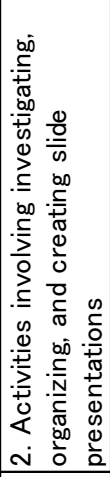 & 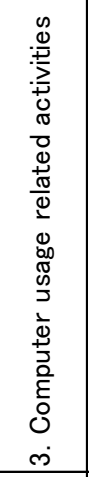 & Total & 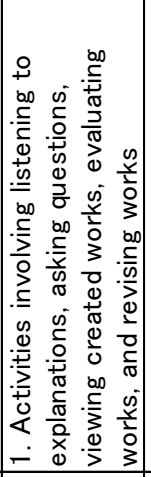 & 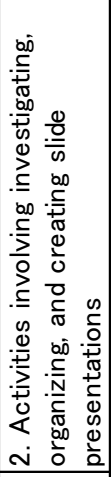 & 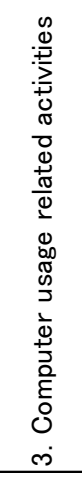 \\
\hline $\begin{array}{l}\text { I. Consciousness related to being interested, } \\
\text { studying, deepening ones understanding, } \\
\text { setting tasks, and carrying out tasks }\end{array}$ & 1385 & 1373 & 646 & 3404 & 1420.2 & 1110.9 & 872.9 \\
\hline $\begin{array}{l}\text { II. Consciousness related to communicating, } \\
\text { collaborating, and evaluating }\end{array}$ & 444 & 75 & 57 & 576 & 240.3 & 188.0 & 147.7 \\
\hline III. Consciousness related to computer & 104 & 64 & 485 & 653 & 272.4 & 213.1 & 167.4 \\
\hline Total & 1933 & 1512 & 1188 & 4633 & 1933 & 1512 & 1188 \\
\hline & \multicolumn{3}{|c|}{ Adjusted residual } & & \multicolumn{3}{|c|}{ Significance probability } \\
\hline $\begin{array}{l}\text { I. Consciousness related to being interested, } \\
\text { studying, deepening ones understanding, } \\
\text { setting tasks, and carrying out tasks }\end{array}$ & -2.4 & 18.6 & -17.3 & & & $* * *$ & \\
\hline $\begin{array}{l}\text { II. Consciousness related to communicating, } \\
\text { collaborating, and evaluating }\end{array}$ & 18.4 & -10.7 & -9.2 & & $* * *$ & & \\
\hline III. Consciousness related to computer & -14.4 & -13.4 & 30.7 & & & & *** \\
\hline
\end{tabular}

This found that frequencies were significantly biased $\left(\chi^{2}(4)=1134.4, \mathrm{p}<.001\right)$. The residual analysis was conducted. In cells recognized as significant in the results, cells with positive residual values were the same as the cross-tabulation table in Table 3 for ST and PI combined as shown in the bottom right of Table 5.

\subsection{Changes in evaluations by others through two viewings of $S T$ and PI works}

After viewing works twice, students evaluated other students' works on a scale of 1 to 5 for 17 evaluation items, entered their evaluations in evaluation sheets, and submitted the evaluation sheets. The five point scale was as follows: "1. Contents have not been sufficiently written and the work falls significantly below the required level; 2 . Contents do not meet the required level; 3 . Contents generally meet the required level; 4 . Contents fully meet the required level; 5. Contents significantly exceed the required level."
4.5.1. Increases in evaluations by others for ST works. 31 respondents performed evaluations for the first and second ST work. Significant difference test was performed on increases in the first and second evaluations from others for works one and two, and on increases between evaluations from others in work one and work two. The results are shown in $6^{\text {th }}$ and $10^{\text {th }}$ columns of Table 6 . The blank spaces in Table 6 indicate that the corresponding items were not investigated.

The overall average evaluation scores for the two evaluations for ST works one and two were checked for paired significant difference, and significance differences were found for both $(\mathrm{t}(402)=2.28$, $\mathrm{p}<0.05)$ and $(\mathrm{t}(464)=5.81, \mathrm{p}<0.001)$. Overall, this indicated that evaluations by others for both works increased. This has already been reported. 
Table 5. Results of $\chi^{2}$ test calculation and residual analysis of cross-tabulation based on PI consciousness and activity clusters

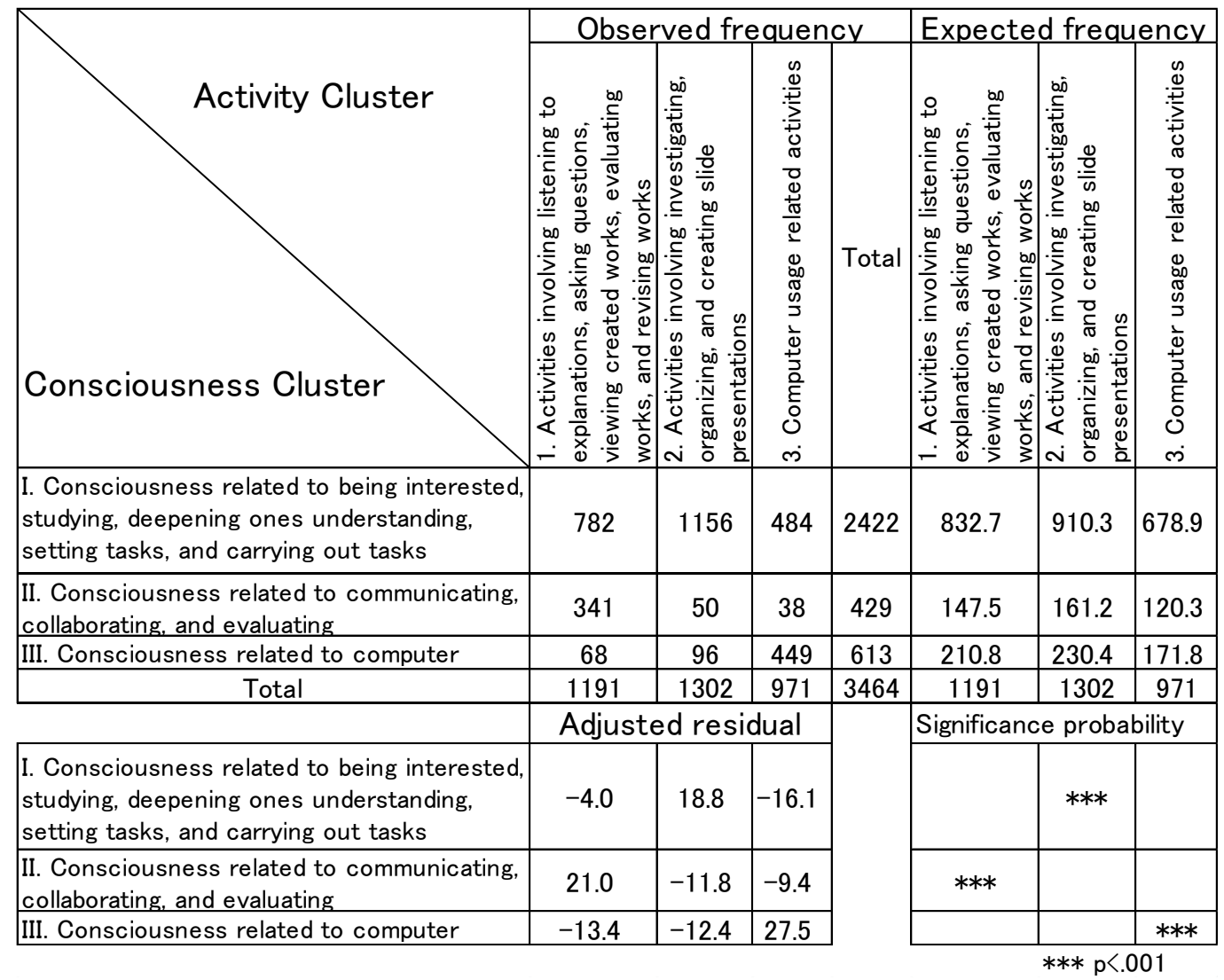

Paired significant difference test for average evaluation scores for the first and second evaluations for work one, for each question item, found that there were significant increases for nine items $((1),(3),(4)$, (6), (7), (8), (9), (10), and (16)) as shown in the $6^{\text {th }}$ column of Table 6 . There was a trend for question item (2) to improve significantly. The same analysis performed for work two found significant improvements for all items ((1) through (16)) as shown in the $10^{\text {th }}$ column of Table 6 . This showed that there were more improvements in evaluations by others for work two than there were for work one.

Next, paired significant test was performed for the overall average evaluation scores for the two works. The results are shown in $12^{\text {th }}$ column of Table 6 . This indicated that a significant difference existed $(\mathrm{t}(402)=2.27, \mathrm{p}<0.05)$. For each question item, paired significant test was performed of the increases in evaluations by others of works one and two. This found that there were significant differences for seven items ((1), (2), (6), (7), (11), (14), and (15)) as shown in $12^{\text {th }}$ column of Table 6 . There was a trend for question items (3) and (4) to exhibit significant differences. This showed that there were more improvements in evaluations by others for work two than there were for work one for these nine items.
4.5.2. Activities contributing to PI consciousness improvements. 26 respondents performed evaluations for the first and second PI work. Significant difference test was performed on increases in the first and second evaluations from others for works one and two, and on increases between evaluations from others in work one and work two. The results are shown in $16^{\text {th }}$ and $20^{\text {th }}$ column of Table 6 . The blank spaces in Table 6 indicate that the corresponding items were not investigated.

The overall average evaluation scores for the two evaluations for PI works one and two were checked for paired significant difference, and significance differences were found for both $(\mathrm{t}(441)=9.78$, $\mathrm{p}<0.001)$ and $(\mathrm{t}(441)=5.06, \mathrm{p}<0.001)$. Overall, this indicated that evaluations by others increased for both works. This has already been reported.

Paired significant differences test for average evaluation scores for the first and second evaluations for work one, for each question item, found that there were significant increases for seven items ((4), (5), (11), (14), (15), (16), and (17)) as shown in $16^{\text {th }}$ column of Table 6 . There was a trend for question item (3) to exhibit significant differences. The same analysis performed for work two found significant improvements for all items ((1) through (17)) as shown in $20^{\text {th }}$ column of Table 6 . This showed that 
there were more improvements in evaluations by others for work two than there were for work one.

Next, paired significant test was performed for the overall average evaluation scores for the two works. The results are shown in $22^{\text {nd }}$ column of Table 6 . This indicated that no significant difference existed $(\mathrm{t}(441)=0.76, \mathrm{p}>0.05)$. For each question item, paired significant test was performed of the increases in evaluations by others of works one and two. This found that there were significant differences for only three items $\left((14),(15)\right.$, and (16)) as shown in $22^{\text {nd }}$ column of Table 6 . This showed that there were more improvements in evaluations by others for work two than there were for work one for these three items. There was a trend for question items (6), (10), and (13) to exhibit significant differences. This showed that there were more improvements in evaluations by others for work two than there were for work one for these three slide-related items.

4.5.3. Comparison of increases in evaluations by others for ST and PI works. In order to compare increases for work one for both ST and PI, nonpaired significant difference test was performed on overall increases. The results are shown in $24^{\text {th }}$ column of Table 6 . This indicated that no significant difference existed $(\mathrm{t}(740)=0.02, \mathrm{p}>0.05)$. We also found that there were almost no differences in increases for work one between ST and PI.

For each question item, non-paired significant difference test was performed of the increases in evaluations by others of ST and PI work one. This found that there were no significant differences for any of the question items for work one between ST and PI, as shown in $24^{\text {th }}$ column of Table 6.

In order to compare increases for work two for both ST and PI, non-paired significant difference test was performed on overall increases. The results are shown in $26^{\text {th }}$ column of Table 6 . This indicated that no significant difference existed $(\mathrm{t}(854)=1.47$, $\mathrm{p}>0.05)$. We found that there were no overall differences in increases for work two between ST and PI.

For each question item, non-paired significant difference test was performed of the increases in evaluations by others of work two. This found that there were significant differences for four items ((9), (10), (11), and (14)) as shown in $26^{\text {th }}$ column of Table 6. There was a trend for question item (13) to exhibit significant differences. This showed that there were more improvements in evaluations by others for ST work two than there were for PI work two for these five items.

Table 6. Results of significant difference test of evaluations by others through two viewings of ST and PI works

\begin{tabular}{|c|c|c|c|c|c|c|c|c|c|c|c|c|c|c|c|c|c|c|c|c|c|c|}
\hline \multirow{3}{*}{$\begin{array}{l}\text { Clasifi } \\
\text { cation }\end{array}$} & \multirow{3}{*}{ Qustion Items } & \multicolumn{9}{|c|}{ Storytelling (ST) } & \multicolumn{8}{|c|}{ Product Introduction (PI) } & \multicolumn{4}{|c|}{$\begin{array}{c}\text { Comparison between } \\
\text { two themes }\end{array}$} \\
\hline & & \multicolumn{4}{|c|}{$\begin{array}{l}\text { First work (self- } \\
\text { awareness) S1 }\end{array}$} & \multicolumn{4}{|c|}{$\begin{array}{c}\text { Second work (story for } \\
\text { children) S2 }\end{array}$} & $\begin{array}{c}\text { Comparison } \\
\text { between } \\
\text { two works }\end{array}$ & \multicolumn{4}{|c|}{ First work (product) P1 } & \multicolumn{3}{|c|}{ Second work (book) P2 } & $\begin{array}{c}\text { Comparison } \\
\text { between } \\
\text { two works }\end{array}$ & \multicolumn{2}{|c|}{$\begin{array}{l}\text { The first } \\
\text { works } \\
\text { S1\&P1 }\end{array}$} & \multicolumn{2}{|c|}{$\begin{array}{l}\text { The second } \\
\text { works } \\
\text { S2\&P2 }\end{array}$} \\
\hline & & $\mathrm{m}$ & SD & $t$ & 0 & $\mathrm{~m}$ & SD & $t$ & $p$ & $p$ & $\mathrm{~m}$ & SD & $t$ & $p$ & $\mathrm{~m}$ & SD & $t$ & $p$ & t & $p$ & $t$ & $p$ \\
\hline \multirow{5}{*}{ 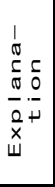 } & (1) Is the composition of the whole explanation appropriate? & 0.15 & 0.26 & $3.06 *$ & & 0.36 & 0.29 & 6.61 & *** & $2.93 * *$ & 0.14 & 0.46 & 1.49 & & 0.26 & 0.31 & $4.16 * *$ & * $\quad 1.07$ & 0.00 & & 1.17 & \\
\hline & (2) Does the explanation accord with a title? & 0.10 & 0.29 & $1.93+$ & & 0.32 & 0.31 & 5.66 & *** & $2.85 * *$ & 0.08 & 0.48 & 0.85 & & 0.23 & 0.30 & $3.72 * *$ & 1.26 & 0.00 & & 1.16 & \\
\hline & (3) Are you interested in explanation? & 0.15 & 0.34 & $2.46 *$ & & 0.30 & 0.30 & 5.53 & *** & $1.75+$ & 0.14 & 0.37 & $1.82+$ & & 0.25 & 0.35 & $3.60 * *$ & 1.14 & 0.00 & & 0.55 & \\
\hline & (4) Is there a contrivance of clarity in explanation? & 0.18 & 0.30 & $3.30 *$ & & 0.32 & 0.28 & 6.28 & **** & $1.81+$ & 0.14 & 0.31 & $2.20 *$ & & 0.20 & 0.27 & $3.79 * *$ & * 0.75 & 0.01 & & 1.56 & \\
\hline & (5) Can you understand the book which you were introduced? & & & & & & & & & & 0.28 & 0.46 & $3.00 *$ & & 0.25 & 0.33 & $3.81 * *$ & * 0.26 & & & & \\
\hline \multirow{8}{*}{$\begin{array}{l}0 \\
0 \\
0 \\
\frac{1}{s}\end{array}$} & (6) Does each slide accord with explanation? & 0.16 & 0.26 & $3.31 *$ & & 0.34 & 0.34 & 5.52 & **** & $2.35 *$ & 0.04 & 0.42 & 0.51 & & 0.25 & 0.32 & $3.93 * *$ & * $1.97+$ & 0.02 & & 1.06 & \\
\hline & (7) Is a slide devised to understand explanation? & 0.16 & 0.28 & $3.10 *$ & & 0.32 & 0.29 & 6.04 & *** & $2.12 *$ & 0.11 & 0.40 & 1.32 & & 0.23 & 0.32 & $3.58 * *$ & 1.18 & 0.01 & & 1.09 & \\
\hline & (8) Is the composition of the whole slide appropriate? & 0.21 & 0.26 & $4.46 *$ & & 0.27 & 0.28 & 5.32 & *** & 0.82 & 0.07 & 0.41 & 0.84 & & 0.22 & 0.24 & $4.47 * *$ & * 1.54 & 0.03 & & 0.80 & \\
\hline & (9) Is the background of the slide appropriate? & 0.23 & 0.31 & $3.97 *$ & & 0.29 & 0.31 & 5.15 & *** & 0.78 & 0.11 & 0.36 & 1.49 & & 0.11 & 0.23 & $2.39 *$ & 0.04 & 0.02 & & $2.36 *$ & \\
\hline & (10) Are the size and the color of the letter appropriate? & 0.20 & 0.28 & $3.79 *$ & & 0.28 & 0.26 & 5.82 & *** & 1.16 & -0.04 & 0.39 & 0.52 & & 0.12 & 0.27 & $2.25 *$ & $1.73+$ & 0.05 & & $2.13 *$ & \\
\hline & (11) Is the thing using for explanation appropriate? & 0.08 & 0.36 & 1.23 & & 0.31 & 0.29 & 5.98 & $* * *$ & $2.80 * *$ & 0.19 & 0.41 & $2.22 *$ & & 0.12 & 0.21 & $2.95 * *$ & 0.70 & 0.02 & & $2.80 *$ & \\
\hline & (12) Is the object performing animation appropriate? & & & & & 0.28 & 0.29 & 5.33 & **** & & 0.04 & 0.40 & 0.53 & & 0.20 & 0.26 & $3.95 * *$ & * 1.68 & & & 1.05 & \\
\hline & (13) Is the target movement performing animation smooth? & & & & & 0.29 & 0.29 & 5.55 & *** & & 0.01 & 0.38 & 0.12 & & 0.17 & 0.24 & $3.44 * *$ & $1.74+$ & & & 1.71 & \\
\hline \multirow{5}{*}{$\begin{array}{l}5 \\
0 \\
\frac{5}{4} \\
\sigma \\
\frac{1}{\pi} \\
z\end{array}$} & (14) Is it easy to hear the voice? & -0.08 & 0.40 & 1.06 & & 0.55 & 0.29 & 10.18 & *** & $6.94 * * *$ & 1.41 & 0.66 & $10.55 *$ & & 0.32 & 0.26 & $6.15 * *$ & * $7.70 * * *$ & 0.19 & & $2.94 *$ & \\
\hline & (15) Are sound and BGM appropriate? & 0.03 & 0.36 & 0.39 & & 0.29 & 0.31 & 5.15 & *** & $3.10 * *$ & 1.01 & 0.79 & $6.29 *$ & & 0.23 & 0.38 & $2.95 * *$ & $4.48 * * *$ & 0.11 & & 0.70 & \\
\hline & (16) Is the time distribution appropriate? & 0.18 & 0.35 & $2.79 *$ & & 0.26 & 0.30 & 4.70 & *** & 0.93 & 0.54 & 0.83 & $3.19 *$ & & 0.24 & 0.23 & $5.36 * *$ & * 1.70 & 0.04 & & 0.20 & \\
\hline & (17) Is the narration devised to understand explanation? & & & & & & & & & & 1.19 & 0.84 & $6.89: *$ & & 0.24 & 0.19 & $6.44 * *$ & $* \quad 5.49: * * *$ & & & & \\
\hline & Average & 0.13 & 0.33 & $2.26 *$ & & 0.32 & 0.30 & 5.81 & & $2.27 *$ & 0.32 & 0.68 & $9.78 *$ & & 0.21 & 0.21 & $5.06 * *$ & $\begin{array}{l}* \quad 0.76 \\
\end{array}$ & 0.02 & & 1.47 & \\
\hline
\end{tabular}




\section{Discussion}

\subsection{Activities contributing to consciousness improvements based on cluster analysis using table formed by the junction of ST and PI cross-tabulation table}

From Table 3, which indicates the results of $x^{2}$ test and residual analysis of a cross-tabulation table including both ST and PI, we determined that "1. Activities involving listening to explanations, asking questions, viewing created works, evaluating works, and revising works" contributed to the increase of "II. Consciousness related to communicating, collaborating, and evaluating." This means that the processes of listening to explanations, listening to friends, asking friends questions, viewing slide presentations, evaluating slide presentations, revising slide presentations, and the like, all parts of the slide presentation creation activity process, improved students' abilities to communicate based on an understanding of the importance of collaboration within the project, and students' evaluation activities.

"2. Activities involving investigating, organizing, and creating slide presentations," contributed to the increase of "I. Consciousness related to being interested, studying, deepening ones understanding, setting tasks, and carrying out tasks." This means that within the slide presentation creation activity process, students improved their abilities of investigating contents to introduce, organizing the findings of these investigations, creating slide presentations, developing an interest in the field, learning and deepening ones understanding, setting tasks, and implementing tasks.

"3. Activities related to computer usage" contributed to the increase of "III. Consciousness related to computer." This means that using computers improved students' interest in computers, understanding of computers, computer operation skills, and broadening their usage methods and usage scenarios.

\subsection{Comparison of ST and PI activities contributing to consciousness improvements}

Tabulation of frequencies for cells of individual clusters derived from the ST cross-tabulation table and subsequent $\chi^{2}$ test and residual analysis found that the results were the same as the cross-tabulation table for ST and PI combined in Table 3. Likewise, tabulation of frequencies for cells of individual clusters derived from the PI cross-tabulation table and subsequent $\chi^{2}$ test and residual analysis found that the results were the same as the cross-tabulation table for ST and PI combined in Table 3.
Based on this, we determined that ST and PI activities were roughly equally effective in improving consciousness. ST's themes of "selfunderstanding" and "children's stories" were selected to improve students' self-analysis abilities when seeking employment, and their understanding of the meaning of work. The PI themes of "product introductions" and "book introductions" were selected to cultivate students' planning abilities, project development abilities, task-setting abilities, and abilities necessary for work. As has already been reported, these objectives were mostly met. This would appear to indicate that even for different objectives and themes, provided that the activities performed in and out of class are roughly the same, the consciousness improvements they produce will also be roughly identical.

\subsection{Changes in evaluations by others through two viewings of ST and PI works}

5.3.1. Consciousness improvements for individual works. As has already been reported, overall evaluations by others improved for both ST works one and two. For each ST question item, paired significant difference test was performed of average evaluation scores by other for works one and two. This found that there were significant differences for nine items for work one, and for all of 15 items for work two. We also found that there were more improvements in evaluations by others for work two than there were for work one. This is believed to be because by the point of the creation of work two, students had already become used to the slide presentation creation process and were able to create better works, receiving a high evaluation.

As has already been reported, overall evaluations by others improved for both PI works one and two. For each PI question item, with regard to the average of both evaluation scores by others, there was a significant increase for seven items for work one, and for all of 17 items for work two. This showed that there were more improvements in evaluations by others for work two than there were for work one. This is believed to be due to the same reasons as for ST.

5.3.2. Comparison of the two works for each theme. Next, the results of paired significant difference test of overall average scores of others' evaluations for the two ST works indicated that there were more improvements in evaluations by others for work two than there were for work one. This is believed to be due to the same reasons as indicated above.

No significant differences were found in the overall average evaluation scores for the two PI works. This indicates that there were no overall differences in evaluations by others for the two 
works. With regard to comparisons of others' evaluations for works one and two on an individual item basis, there were more improvements in evaluations by others for work one than there were for work two for three narration-related items. With regard to the three slide-related items, there were more improvements in evaluations by others for work two than there were for work one. With regard to narration, we believe this is because for many students this was their first time recording narration, so there was more growth for work one than work two. With regard to slides, on the other hand, we believe this is because the students grew used to creating slides, so there was a greater increase for work two.

5.3.3. Comparison of evaluations by others for ST and PI works. We found that there were no overall differences in increases in overall others' evaluations between ST work one and PI work one, nor between ST work two and PI work two. We expect that in the future, even if themes differ, increases in others' evaluations will be overall equivalent.

\section{Conclusions}

We designed and carried out classes that employed active learning, in which students used PowerPoint to create storytelling works and product introduction slide presentations. For both projects, students decided what they wanted to introduce themselves, investigated related content, considered the introduction explanations they would provide, created slides, added animation, and recorded narration. Students viewed each other's slide presentations and learned from each other. They evaluated each other and provided comments regarding each other's works. They then revised their slide presentations, presented them to each other again, and evaluated each other again. This report has discussed the implementation of these classes, whose objectives were to increase self-understanding through the ST and to increase expressive abilities, planning abilities, and proposal abilities through the PI by way of active evaluation activities and revision activities, through the process of mutual activity, coordinating with other students and completing works.

The findings of these classes are summarized below.

(1) The activity clusters that contributed to the consciousness clusters were as below. "1. Activities involving listening to explanations, asking questions, viewing created works, evaluating works, and revising works" contributed to the increase of "II. Consciousness related to communicating, collaborating, and evaluating." "2. Activities involving investigating, organizing, and creating slide presentations," contributed to the increase of "I.
Consciousness related to being interested, studying, deepening ones understanding, setting tasks, and carrying out tasks." "3. Computer usage related activities" contributed to the increase of "III. Consciousness related to computer."

(2) Activities in ST and PI were roughly equally effective in improving consciousness.

(3) There were more improvements in evaluations by others for work two than there were for work one for both ST and PI.

(4) There were no overall differences in increases in overall others' evaluations between ST and PI for work one, nor between ST and PI for work two.

\section{Future Work}

In the future, we would also like to analyze and report on blended classes which have already been carried out but not yet reported on. We would like to analyze students' reactions by clickers to blended classes, and report on their effectiveness.

\section{References}

[1] Ministry of Education, Culture, Sports, Science and Technology Council (MECSST) (2012) 'Continue Learn towards the Qualitative Transformation of University Education in order to Bild a New Future - to the University to Continue Learning throughout the Life and Foster the Ability to Think proactively' (Report), http://www.mext.go.jp/b_menu/shingi/chukyo/chukyo0/tou shin/1325047.htm (10 January 2015).

[2] Miyaji, I. and Yoshida, K. (2005) 'Practice and Learning Effect of Education by blending of Lecture and eLearning', Transactions of Japanese Society for Information and Systems in Education, 22(4), 230-239.

[3] Miyaji, I. (Ed.) (2009) Toward Blended Learning from E-learning, Japan, Kyoritu-Shuppan, Tokyo.

[4] Miho, N., Honda, S., Mori, T. and Mizokami, S. (2016) 'Relationship with Attitude to Homework in Flipped Classroom and Active Learning', Japan Journal of Educational Technology, 40(Suppl.), 161-164.

[5] Tsuji, Y. and Sugiyama, S. (2016) 'A Comparison of Learning Effects between Active Learning and Traditional Learning for Identical Lecture', Japan Journal of Educational Technology, 40(Suppl.), 45-48.

[6] Koyama, A. and Mizokami, S. (2018) 'The Effect of Attitudes toward Lectures on Learning Outcomes Mediated by Attitudes toward Active Learning', Educational Technology Research, 41(1), 69-76.

[7] Miyaji, I. (2010) 'The Effects of Digital Storytelling through the Strategy of Phased Evaluation and Correction', ITHET2010 Proceedings - 9th International Conference on Information Technology Based Higher Education and Training, pp.138-143, Cappadocia, Turkey. 
[8] Miyaji, I. (2012) 'Effects of Creating Three Kinds of Digital Storytelling on Student Attitude', Journal of Modern Education Review, 2(4), 238-259.

[9] Miyaji, I. (2016) 'Improvement in Computer Literacy through Creating Digital Storytelling', American Journal of Educational Research, 4(1), 54-63. doi: 10.12691/education-4-1-10.

[10] Miyaji, I. (2015) 'Useful Activities for Improving Consciousness and Change of Evaluation by Others in Class for Creating Slides to Present Product', International Journal for Cross-Disciplinary Subjects in Education (IJCDSE), Special Issue 5(Issue 4), 2661-2671. doi: 10.20533/ijcdse.2042.6364.2015.0362.

[11] Miyaji, I. (2017) 'Change of Awareness and Characteristics of Student Groups in Class Creating Slides to Introduce Books with PowerPoint'. Journal of Studies on Education, 7(3), 29-47. doi:10.5296/jse.v7i3.11354.

[12] Miyaji, I. (2016) 'Classification and Characteristics of Student Groups Using Change of Attitude in Class for Creating Slides to Present Product', Asian Education Studies, 1(2), 56-68. doi:10.20849/aes.v1i2.

[13] Miyaji, I. (2017) 'Useful Activities and Peer Evaluation in Creating PowerPoint Slides to Introduce a Book'. International Journal for Cross-Disciplinary Subjects in Education (IJCDSE), 8(issue 2), 3034-3045. doi: 10.20533/ ijcdse.2042.6364.2017.0411.

[14] Miyaji, I. (2019) 'Comparison of Awareness and Computer Literacy in Classes through Creation of Storytelling and Product Introduction Slides', American Journal of Education and Learning, 4(2), 272-291. doi: 10.20448/804.4.2.272.291. 